\title{
Postpartum Normotansif PRES Olgusu
}

\author{
A Case of Postpartum Normotensive PRES
}

Müge Kuzu, Sabiha Tezcan, Mine Hayriye Sorgun, Canan Togay Ișıkay

Ankara Üniversitesi Tıp Fakültesi Nöroloji Anabilim Dalı

Giriș: Posterior reversible ensefalopati sendromu (PRES) baș ağrısı, konfüzyon, fokal nörolojik semptomların eșlik ettiği hızlı gelișen nörolojik tutulumun yanında bilgisayarlı beyin tomografi (BBT) ya da kranyal manyetik rezonans görüntülemede (MRG) tipik görüntüleme paterni ile seyreden bir sendromdur. Eklampsi/preeklampsi PRES'in iyi bilinen nedenlerindendir. Biz, gebelikte ve postpartum dönemde kan basıncı normal seyreden bir PRES olgusunu sunuyoruz.

Olgu: 33 yașındaki kadın hasta; postpartum birinci haftada baș ağrısı, ateș yüksekliği $\left(39^{\circ}\right)$, bulantı-kusma, görme bulanıklığı, vücutta yaygın kasılma ve bilinç kaybı yakınmaları ile acil servise bașvurdu. Hastanın gebelik sırasındaki takiplerinde kan basıncı yüksekliği olmamıștı. Hastanın nörolojik muayenesinde solda görme keskinliğinde azalma (20/100) ve sol hemihipoestezisi mevcuttu. Hastaya menenjit ön tanısı ile lomber ponksiyon (LP) yapıldı. Beyin omurilik sıVısı (BOS) açılıș basıncı $13 \mathrm{~cm} / \mathrm{su}$ bulundu. BOS bulguları normaldi. Ardından yaklașık üç dakika süren jeneralize tonik klonik nöbeti oldu. Nöbet sonrası yeniden çekilen kranyal MRG'de FLAIR sekansında sağda oksipitalde hiperdens alan saptandı. Hastaya valproik asit 1000 mg bașlandı. 24 saat sonra çekilen kontrol kranyal MRG'de FLAIR sekansında bilateral oksipital bölgede tübüler hiperdens yapı gözlemlendi. Kranyal manyetik rezonans venografisi (MRV) ve vaskülit belirteçleri normaldi. Bu kranyal MRG bulguları PRES ile uyumlu bulundu. Hastanın 1 ay sonraki kontrolünde nörolojik muayene bulguları ve kranyal MRG'si normale dönmüștü. Ardından hastanın valproik asidi azaltılarak kesildi.

Tartıșma: Hastada baș ağrısı, nöbet ve görme kaybı olması, radyolojik görünümün PRES ile uyumlu olması, takiplerinde kranyal MRG görünümünün normale dönmesi ve görme kaybının azalması PRES tanımızı destekledi. Sonuç olarak normotansif de olsa kliniği uyumlu olan postpartum kadınlarda PRES akla gelmelidir.

Anahtar Sözcükler: Posterior Reversible Ensefalopati Sendromu, Postpartum, Baș Ağrısı, Nöbet

Introduction: Posterior reversible encephalopathy syndrome (PRES) is a syndrome which includes headache, confusion, focal neurologic symptoms, seizures and visual loss with fast occurring neurological involvement and typical imaging findings in cranial computerized tomography (CCT) or cranial magnetic resonance imaging (CMRI). Preeclampsia/eclampsia is the most common cause of PRES. We are introducing you a PRES case with normal blood pressure at post-partum period.

Case: A 33-year-old woman within one week postpartum (C/S) was admitted to the emergency department with headache, nausea and vomiting, visual loss, high fever, loss of consciousness and full body muscle contractions. Peripartum period had been uneventful with no history of hypertension before or during pregnancy. Left hemihipoestesia and reduced visual acuity in left side (20/100) involved in neurological examination. Lumber puncture (LP) was performed for meningitis. There was no significant finding in cerebrospinal fluid examination (CSF). During follow-up one episode of generalized tonic clonic seizure which lasted three minutes occurred. Bilateral occipitale hiperintens lesions were determined at FLAIR sequence in MRI of brain following seizure. Valproic acid (1000 $\mathrm{mg}$ /day) was started. After 24 hours, control MRI showed tubuler hyperintensity located in bilateral occipital lob. She had normal MR venography and vasculitis markers. The MRI findings were suggesting PRES. The final diagnose was comfirmed as PRES. After one month, neurological examination and MRI was normal. Valporic acid was reduced and stopped.

Discussion: Headache, seizures, visual loss, radiological finding with regression of MRI findings and improvement of visual loss at follow-up period are supporting the PRES diagnose. In conclusion PRES should be considered as a potential cause of acute onset focal neurological deficit in postpartum women despite being normotansive.

Key words: Posterior Reversible Encephalopathy Syndrome, Postpartum, Headache, Seizure

Posterior reversible ensefalopati sendromu (PRES) baş ağrisı, konfüzyon, kortikal körlük, mental durum değişikliği, nöbet, letarji, stupor, fokal nörolojik semptomlar, görme bozuklukları gibi hızlı gelişen nörolojik tutulumun yanı sira bilgisayarlı beyin tomografisi (BBT) ya da kranyal manyetik rezonans görüntülemede (MRG) tipik görüntüleme paterni ile seyreden bir sendromdur (1). Posterior serebral hemisferlerde, özellikle de bilateral parietooksipital bölgelerde beyaz cevherdeki ödem görünümü PRES’in klasik radyolojik görünümüdür (2). Semptomlar akut başlangıçlı olabilir ya da birkaç gün içinde ortaya çıkabilir. Orta ve ileri hipertansiyon olguların \%70-80’inde görülür (3). Etiyolojisinde genellikle hipertansiyon, eklampsi ve immünsupresif ajanlar vardir (2-5). Eklampsi/preeklampsi, PRES'in iyi bilinen nedenlerindendir (3). Biz, gebelikte ve postpartum dönemde kan basinc1 normal seyreden bir PRES olgusunu sunuyoruz. 


\section{OLGU SUNUMU}

Otuz-üç yașında kadın hasta baș ağrısı, bulant1-kusma, görme bulanıklığ1, vücutta yaygın kasılma ve bilinç kaybı yakınmaları ile acil servise başvurdu. Hasta 7 gün önce spinal anestezi eşliğinde sezeryan ile doğum yapmıştı. Üç gün sonra başının sağ tarafinda belirgin, analjezik ile geçmeyen baș ağrısı ile birlikte $39^{\circ} \mathrm{C}$ ateşi olmuştu. Buna bulantı ve kusma eșlik etmiști. Hastanın gebelik takiplerinde hiç kan basınc1 yüksekliği olmamıştı. Diyetle kontrol altına alinan gestasyonel diyabet saptanmıştı. Soygeçmişinde özellik yoktu.

Hastanın genel fizik muayenesi normaldi. Nörolojik muayenesinde solda hemihipoestezisi mevcuttu. Görme keskinliği ise solda $20 / 100$ ve sağda 100/100 idi. Hastaya menenjit ön tanis1 ile lateral dekübit pozisyonunda lombar ponksiyon (LP) yapildı. Beyin omurilik sıvısı (BOS) açılış basınc1 13 $\mathrm{cm} / \mathrm{su}$ bulundu. BOS'da hücre yoktu ve biyokimya değerleri normaldi. Buna rağmen ateşinin $37.5{ }^{\circ} \mathrm{C}$ olması üzerine profilaktik antibiyoterapiye başland1. Takibinde BOS kültüründe üreme olmadı. BOS'da HSV-1, HSV2, VZV, EBV, CMV, HHV6, Enterovirus, Streptococcus pneumoniae, Neisseria meningitidis, Haemophilus influenzae, Listeria monocytogenes ve Grup B streptokok PCR tetkikleri negatif idi. Hastaya çekilen BBT ve kranyal MRG'de anlamlı patoloji saptanmadı. Hastanın takipte yaklaşık üç dakika süren jeneralize tonik klonik nöbeti oldu. Nöbet sonrası yeniden çekilen kranyal MRG'de fluidattenuated inversion recovery (FLAIR) sekansinda bilateral parieto-oksipitalde hiperintens alanlar saptandi. Hastaya valproik asit $1000 \mathrm{mg} /$ gün başland1. 24 saat sonra çekilen kontrol kranyal MRG'de FLAIR sekansinda bilateral oksipital bölgede tübüler hiperdens yap1 gözlemlendi. Kranyal manyetik rezonans venografi (MRV) normaldi. Vaskülit belirteçleri (ANA, Anti ds DNA, antifosfolipid antikorlar1, antiRo, Anti la, anti-SSA, anti -SSB) negatifti.

Kranyal MRG bulguları PRES ile uyumlu bulundu (Şekil 1a-b). Göz hastalıkları tarafindan yapılan bilgisayarlı görme alanında (BSGA) maküler korumalı sağ hemianopsi saptandı (Şekil 2-a).
Mevcut BSGA sonucu kortikal körlük olarak yorumlandi. Dokuzuncu gününde hastanın baş ağrisı geçti. Duyu kusuru düzeldi ve görme bulanılklı̆ geriledi. Görme keskinliği sol gözde 20/100'den 20/50’ye düzelmiști. Has- tanın 1 ay sonraki kontrolünde görme alanındaki bozulma tama yakın düzeldi (Şekil 2-b). Kranyal MRG ise normale döndü (Şekil 3a-b). Ardından hastanın valproik asidi azaltılarak kesildi.

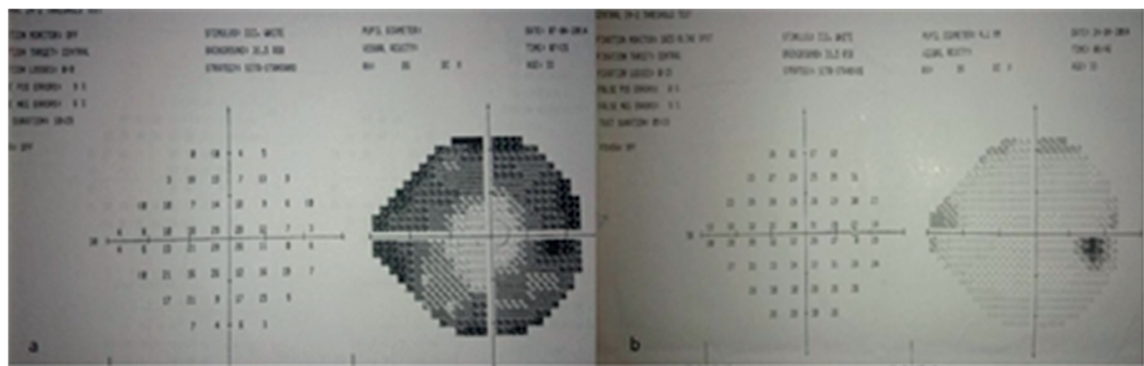

Şekil 1: Kraniyal MRG'de aksiyal FLAIR sekansında bilateral parietooksipital hiperintens gorunum $(a, b)$

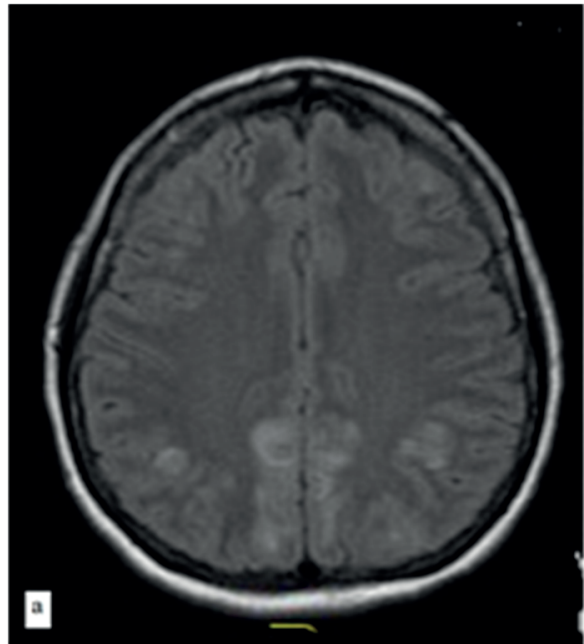

Şekil 2-a: Akut donemde gorme alanı incelemesi,

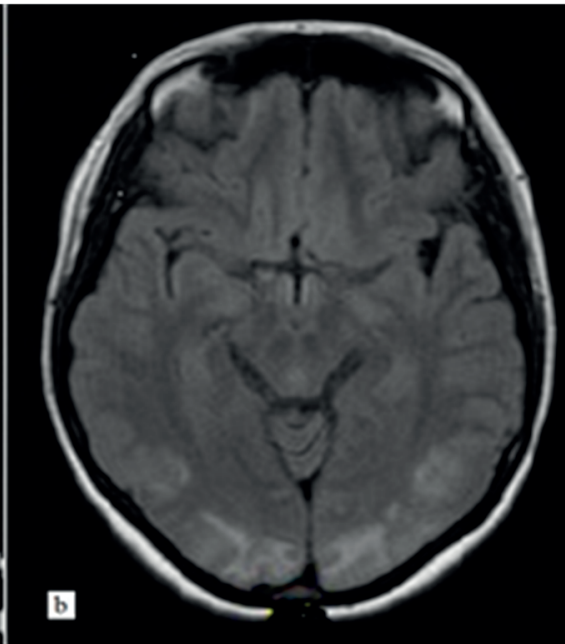

Şekil 2-b: 1 ay sonraki gorme alanı incelemesi

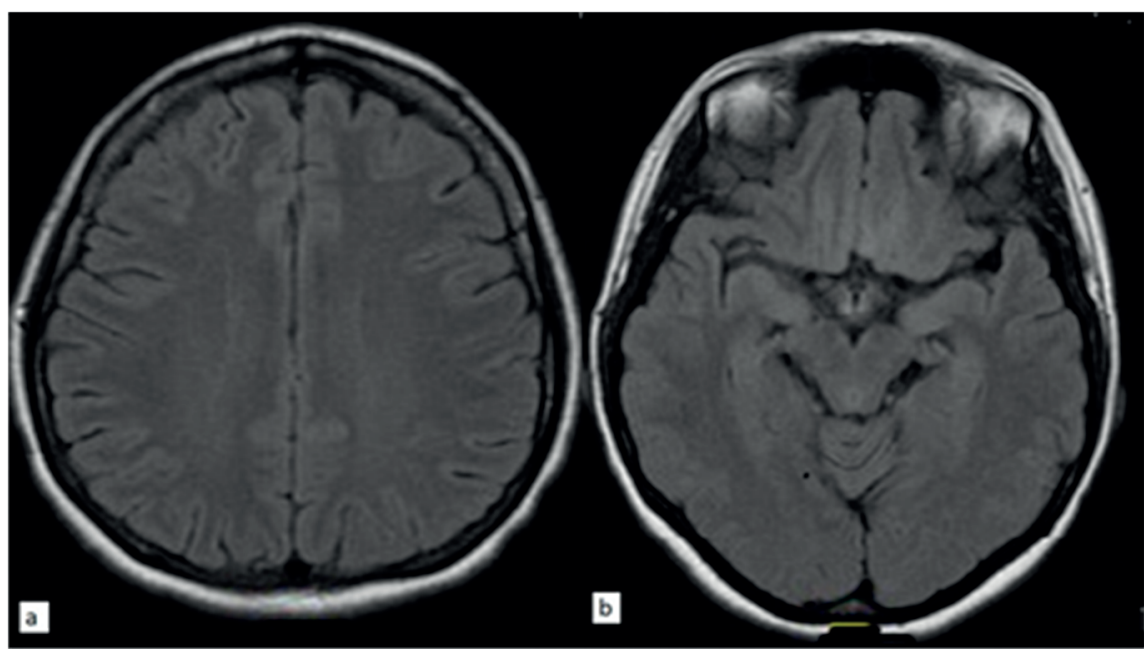

Şekil 3: Bir ay sonraki kontrol kraniyal MRG'de aksiyal FLAIR sekansdaki normal gorunum $(a, b)$ 


\section{TARTISTMA}

Gebelik toksemisinin PRES ile olan ilişkisi iyi tanımlanmıştır (6). Postpartum PRES olguları genelde eklampsi yada preeklampsi ile beraberdir. Fakat nadir de olsa eklapmsi ve preeklampsi olmadan da klinik ve radyolojik olarak PRES olguları görülebilmektedir. Diğer iyi tanımlanmış PRES nedenleri ise hipertansif ensefalopati, üremi, hemolitik üremik sendrom, SLE, siklosporin, takrolimus, sisplatin, interferon alfa ve intratekal metotraksate gibi ilaçlardır $(7,8)$. Otoimmün konnektif doku hastalıkları, trombotik trombostopenik purpura, HIV sendromu, akut intermittan porfiriya ve organ transplatansyonu ile ilgili bildirilmiş olgular da vardir (9).

PRES patofizyolojisi hakkında en çok kabul gören teori, hipertansiyonun neden olduğu serebral otoregülasyon mekanizmalarının yetersizliğini taki-

\section{KAYNAKLAR}

1. Lipstein H, Lee CC, Crupi RS. A current concept of eclampsia. Am J Emerg Med. 2003;21:223-226.

2. Mukherjee P, McKinstry RC. Reversible posterior leukoencephalopathy syndrome: Evaluation with diffusion-tensor MR imaging. Radiology 2000;219:756-765.

3. Siddiqui TS, Irfan-u-haq, Rehman B, et al. Posterior Reversible Encephalopathy Sendrome. J Coll Phycians Pak. 2012;22:168-170.

4. Rykken JB, McKinney AM. Posterior reversible encephalopathy syndrome. Semin Ultrasound CT MR. 2014;35:118-135.

5. O'Kane M, Elhalwagy H, Kumar S, et al. Unusual presentation of PRES in the postnatal period. BMJ Case Rep. 2014;9:2014 ben oluşan hiperperfüzyon ve vazojenik ödemdir. Diğer teori ise vazokonstrüksiyonun ve hipoperfüzyonun beyin iskemisi ve vazojenik ödeme neden olmasidır (10). PRES subkortikal beyaz cevherdeki vazojenik ödemin neden olduğu T2 ağırlıklı ve FLAIR sekanslarda posteriorda belirgin hiperintensite ile karakterizedir. Diffüzyon ağırlıklı görüntüleme (DWI) ve Görünüşteki Difüzyon Katsayısı (ADC) görüntüleri vazojenik ödemle sitotoksik ödem ayrımını yapmada yararlidir (11).

Hipertansiyon PRES için esansiyel değildir ve \%20-40 olguda hipertansiyon olmadan da görülebilmektedir $(11,12)$. Bazı olgularda da hafif yüksek kan basıncı değerleri görülebilmesine rağmen bu değerler otoregülasyonu etkileyecek düzeyde değildir. Yapılan pek çok çalışmada normotansif hastalara kiyasla hafif düzeyde hipertansiyonu olanlarda az miktarda da olsa vazojenik ödem olmas1, bek- lenenin aksine hafif düzeyde hipertansiyonun da serebral otoregülesyonu bozduğu ve bunun PRES’e sebep olduğunun göstergesi olabilir $(12,13)$.

Bizim olgumuzda hastamız gestasyon döneminde düzenli olarak takiplerini yaptırmış ve bu süre zarfinda hiç kan basıncı yüksekliği olmamıştır. Diyetle kontrol altına alınan gestasyonel diyabetes mellitus dişından gebelik dönemini sorunsuz atlatmış bir olgudur. Postpartum dönemde acil başvurularinda ve klinik izleminde de hasta normotansif seyretmiştir. Hastanın baş ağrısı, nöbet ve görme kaybının olmas1, radyolojik görünümün PRES ile uyumlu olması, takiplerinde kranyal MRG görünümünün normale dönmesi ve görme kaybinın azalması PRES tanımızı desteklemektedir. Sonuç olarak normotansif de olsa kliniği uyumlu olan postpartum kadinlarda PRES akla gelmelidir.
6. Ara N, Fugii T, Tsutsumi O. Postpartum eclampsia associated with cortical blindness. Int J Obstet Gynecol 1994;47:287288

7. Chou MC, Lai PH, Yeh LR, et al. Posterior reversible encephalopathy syndrome: Magnetic resonance imaging and diffusion-weighted imaging in 12 cases. Kaohsiung J Med Sci 2004;20:381-388.

8. Saifudeen A, Mudasser S, Kottam G, et al. A Rare cause of visual defect in a postpartum woman. Oman Med J 2010;25:128-130

9. Parisaei M, Derwig I, Yoon J, et al. Posterior reversible leukoencephalopathy in a case of postpartum eclampsia. Am J Obstet Gynecol 2005;193:885-886

10. Bartynski WS. Posterior reversible encephalopathy syndrome, part 2: Contro- versies surrounding pathophysiology of vasogenic edema. AJNR Am J Neuroradiol. 2008;29:1043-1049.

11. Bartynski WS, Boardman JF. Distinct imaging patterns and lesion distribution in posterior reversible encephalopathy syndrome. AJNR Am J Neuroradiol 2007; 28:1320-1327.

12. Bartynski WS, Boardman JF, Zeigler ZR, et al. Posterior reversible encephalopathy syndrome in infection, sepsis, and shock. AJNR Am J Neuroradiol 2006; 27:21792190.

13. Lin JT, Wang SJ, Fuh JL, et al. Prolonged reversible vasospasm in cyclosporin $\mathrm{A}$ : induced encephalopathy. AJNR Am J Neuroradiol 2003; 24:102-104. 
